\title{
Factors associated with neonatal danger signs among high risk mothers during perinatal period
}

\author{
Ayat Masaoud ${ }^{1,2}$, Amal A. Hussein ${ }^{3}$, Eman R. Ahmad*4 \\ ${ }^{1}$ Maternity and Neonatal Health Nursing, College of Nursing, Fayoum University, Fayoum, Egypt \\ ${ }^{1}$ Obstetrics and Gynaecologic Nursing, College of Applied Medical Sciences, Qurayyat, Jouf University, Kingdom of Saudi Arabia \\ ${ }^{3}$ Pediatric and Premature Nursing Department, College of Nursing, Assiut University, Assiut, Egypt \\ ${ }^{4}$ Obstetrics \& Gynecological Nursing Department, College of Nursing, Assiut University, Assiut, Egypt
}

Received: September 3, 2018

DOI: $10.5430 /$ jnep.v9n4p17
Accepted: November 25, $2018 \quad$ Online Published: November 29, 2018

URL: https://doi.org/10.5430/jnep.v9n4p17

\begin{abstract}
Background and objective: Complications during pregnancy and labour increase the risk of perinatal mortality fivefold which in turn has a negative effect on the neonate. Despite several studies have examined the determinants of neonatal mortality, limited studies have explored neonatal danger signs which potentially cause morbidity. This study aimed to assess danger signs observed in neonates at the different times so early, early, and late to identify associated factors with neonatal danger signs \& to determine the relationship between danger signs at different times and maternal danger signs/complications of high risk mothers.

Subjects \& Method: Setting: This study was conducted in the Obstetrics Department at Women's Health Center, Assiut University Hospital, Egypt. Sample: A total of 150 postpartum women and their delivered newborns were included and completed the questionnaire from April to the end of July 2017. Design: A descriptive correlational research design was utilized in this study in which structured interviewer managed questionnaire using face-to-face used to collect data.

Results: The present findings revealed that nearly three-quarters (75.3\%) and more than two-thirds (67.3\%) of the total sample complained of antenatal \& postnatal danger signs respectively and consequently the majority (80\%) of their neonates had so early neonatal danger signs/complications with a most frequent one in the form of neonatal jaundice. A positive significant correlation was apparent between so early \& early neonatal danger signs and maternal antenatal and postpartum danger signs. Educational level, maternal age, occupation \& parity were considered significant factors affected neonatal danger signs.

Conclusions: A highly percentage of neonates were born with so early danger signs. Maternal factors can be used to predict neonatal health condition at birth and 7th days postpartum with marked decline at 28th day postpartum.
\end{abstract}

Key Words: Neonatal danger signs, High risk postpartum, Associated risk factors

\section{INTRODUCTION}

Neonatal period is determined up to first 28 days of life and further divided into so early (birth to less than 24 hours, early (birth to less than 7 days), and late neonatal period (7 days to $<28$ days). It is a vulnerable time in an individual's life so neonatal state of health incorporates a significant impact on future wellbeing and life. ${ }^{[1]}$ As early detection of neonatal illness through identifying neonatal danger signs is an important step towards improving newborn survival. ${ }^{[2]}$

Globally, nearly 130 million neonates are born each year and out of these, 4 million die in the first 28 days of their life as

\footnotetext{
*Correspondence: Eman R. Ahmad; Email: emomedo2@yahoo.com; Address: Obstetrics \& Gynecological Nursing Department, College of Nursing, Assiut University, Assiut, Egypt.
}

Published by Sciedu Press 
estimated by Egyptian Demographic Health Survey (EDHS) report, 2016 and accounts for $40 \%$ of the death of children under the age of 5 years. ${ }^{[2]}$ Most of neonatal deaths occur in low-income and middle-income countries, predominately in Sub-Saharan Africa. ${ }^{[3]}$

In Egypt every year die around 1,400 Egyptian women and half of their newborns died as a result of perinatal complications (Ministry of Health and Population, Egypt, 2011). In this respect, neonatal mortality rate of Egypt declined gradually from 59.6 deaths per 1,000 live births in 1967 to 12.8 deaths per 1,000 live births in 2016. Moreover, about $42 \%$ of the infant deaths in Assiut city occurs within the first 28 days of life. ${ }^{[4]}$

As neonatal period is considered the most hazardous period of life due to varied problems/diseases, which a neonate faces during the perinatal period that entail phase surrounding the time of birth, from the twentieth week of gestation to the twenty-eighth day of newborn life. ${ }^{[3]}$ During this phase high risk mothers who have warning signs as vaginal bleeding, severe headache, vision problems, high fever, swollen hands/face, and reduced fetal movement which indicates the presence of an obstetric complications, it inevitably has negatively effect on the neonate. ${ }^{[5]}$ The majority of these newborns death occurs at home (outside the formal health system) where only a few mothers and families recognize danger signs of newborn illness, for that it is terrible that many of newborn die every year especially when their death is preventable. ${ }^{[3,4]}$

For that more research activities launched and put a great emphasis to enhance maternal health and antenatal care as it is proposed to have an insightful effect on reducing perinatal and neonatal morbidity and mortality. Overall, pregnancy and delivery complications are implicated in more than half of newborn deaths. ${ }^{[6]}$

Perinatal risk is broadly defined as one in which the mother, fetus or newborn is at risk of morbidity or mortality either before, during or after delivery. Potential determinants of neonatal danger signs and factors that would delay for sick newborn treatment were classified into 4 domains: maternal factors, family factors, antenatal factors, and delivery factors. Okawa et al. ${ }^{[7]}$ reported that such these risks especially that arising during pregnancy and labour, increased the risk of perinatal mortality fivefold. All these factors are responsible for $30 \%$ of perinatal morbidity and mortality.

A majority of newborn babies do not develop any danger and critical problems or difficulties which require only minimal care, and can be provided by the mother if duly supervised by a health care provider. High risk mothers are likely to give birth to compromised babies who suffer a large number of serious problems which are predicted through warning signs. ${ }^{[8]}$ Some of these frequently reported as neonatal danger sign includes inability to breastfeed, low or elevated temperature, difficult breathing and history of convulsion constipation/diarrhea. Mohamed et al. ${ }^{[3]}$ recognized the occurrence of these signs will result in high overall sensitivity and specificity to prophesy the need for looking for treatment of the newborn. ${ }^{[7]}$ Early detection of these illness and problems through identifying neonatal danger signs is a vital and critical step towards improving newborn survival and wellbeing as the majority of neonatal morbidity causes are preventable. ${ }^{[5]}$ As previous studies estimated that about $75 \%$ of neonatal deaths can be avoided. ${ }^{[2,3]}$

Among the main causes of perinatal morbidity and mortality high risk pregnancies comprise the commonest one. ${ }^{[9]}$ Integrated Management of newborn and illness program that developed by World Health Organization (WHO) was the one which focused on assessment of neonatal danger signs and applies prompt timely treatment. ${ }^{[3,10]}$ Similarly, Bhutta et al. ${ }^{[1]}$ reported early identification of newborn danger signs by caregivers either mother or health care provider with prompt and appropriate referral serves as backbone of the millennium development goal programs aiming at reduction in neonatal mortality.

Since the health of the mother and the newborn are indistinguishably interrelated, intervention policies must involve antenatal and intrapartum health care of the mother and immediate and routine postpartum care of the mother and neonate to optimally impact perinatal and neonatal health outcomes. ${ }^{[6]}$

\subsection{Significance of the study}

For the last era, neonatal deaths have gained attention on the global policy agenda. ${ }^{[3]}$ Neonatal morbidity and mortality is on increase day by day due to lack of the available resources in developing countries. This can be reduced by proper and timely intervention. Studies in the area of upper Egypt as Assiut Governorate which are rural communities with an average large population by about $(44.54,123,441)$ with low resources remote village ${ }^{[4]}$ portrayed limited neonatal warning/danger signs which potentially cause neonatal morbidity. While many studies have examined factors contributing to neonatal mortality in resource limited settings, few studies have focused on neonatal danger signs and complications. These abnormal health conditions could ultimately lead to life-threatening complications or death. ${ }^{[12,13]}$ Moreover, reducing neonatal morbidity and mortality requires immediate caregiver's recognition of suggestive danger signs in the neonates and visiting the nearby clinic for early treatment. ${ }^{[14]}$ 
Mortality risk may be even higher if the neonate and the mother have multiple danger signs or complications. To address these gaps, the researchers interest to study and explore the incidence of perinatal danger signs or complications, determined the correlations between multiple danger signs and complications in neonates and their mothers that encountered them during perinatal period.

\subsection{Aims of the study}

(1) To assess neonatal danger signs noticed in neonates so early, early and late.

(2) To identify associated factors with neonatal danger signs.

(3) To determine the relationship between neonatal danger signs at different times and maternal danger signs/complications of high risk mothers.

\section{SubJECTS AND METHOD}

\subsection{Research design}

A descriptive correlational research design was utilized in this study.

\subsection{Setting}

This study was conducted in the Obstetrics Department (High risk inpatient, postpartum ward and outpatient clinic) at Women's Health Center, Assiut University Hospital, Egypt. This hospital was chosen as it is an educational tertiary hospital with high turnover of patients as it provides services for all cases that come from rural and urban areas in Assuit governorate and receives all pregnant and puerperal women either low or high risk who delivered either normally or by C.S and received annually approximately 3,000 women delivered by C.S, 6432 delivered normally and approximately 300 high risk women. ${ }^{[15]}$

\subsection{Sample}

A total of 150 postpartum women and their delivered newborns who were admitted to Obstetrics Department from the beginning of April to the end of July 2017, consented to join the study and completed the structured interviewer managed questionnaire were included in the study.

Operational definition of Neonatal danger signs: Neonatal danger signs are signs that complicate the lives of the neonate and occur during the neonatal period. Neonatal period at birth (so early) means during the first 24 hours, early means within the 1 st 7 days and late neonatal period means period from 7 to 28 days postnatal.

\subsection{Tool of data collection}

One tool was developed and used by the researcher after reviewing the related literatures namely; structured interviewer managed questionnaire using face-to-face interviews used for data collection and it entailed 4 parts as the following:

Part 1: Demographic data of participants, which included: Age, level of education, residence, occupation \& telephone number of the mothers.

Part 2: Data related to reproductive history of the studied subjects, it included (weeks of gestation, number of parity, abortions, stillbirths, neonatal deaths, number of living children and number of antenatal clinic visits).

Part 3: Maternal and neonatal data which included: Medical or obstetrical risk factors, history of occurrence of warning signs/complications arising during antenatal and postnatal period, data related current delivery as mode of delivery, indication of C.S, warning signs \& intra-partum complications as maternal data and birth weight, Apgar score, admission to Neonatal Intensive Care Unit (NICU) and its duration and neonatal experience of warning signs as neonatal data.

Part 4: Data related to neonatal follow up, as newborn warning signs /problems, the type of these problems and health seeking behavior during the 1st visit and 2nd visit (at 7 and 28 days respectively).

\subsection{Procedure}

Before conducting the study, an official permission was obtained from the ethical committee in the Faculty of Nursing, Assiut University and from the responsible administrative personnel at the field of work (the directors of woman's health center, the chairman of inpatient Obstetrics department and the outpatient clinic) to carry out the study after explaining the aim of the study. After obtaining the official approval for conducting the study, a verbal informed consent was obtained instead of written one as the participants prefer verbal acceptance rather than being written after explaining the purpose of the study and they have the right to abstain from the study at any time regardless of the cause. Participants were assured that all their data are highly confidential as data was only available to the researchers and the participants.

Participants were interviewed and assessed during their hospital stay in the postpartum ward \& outpatient clinic. The questionnaire was translated into the local language (Arabic) to make data collection process simple and translated back to the English language by translators who are perfect (good in English and Arabic language). Two trained BSc nursing degree holders help the investigator in conducting the data collection process.

The developed questionnaire was critically reviewed by the five juries who are experts in the field of Obstetrics \& Gyne- 
cological nursing and Pediatric nursing to assess the validity of the tool and to avoid any repetition \& content validity index (CVI) was considered, for that the pilot study was carried out on $10 \%$ of participated mothers (15 women) of the sample to test the applicability of the tool; these studied mothers were excluded from the sample as it's done only to evaluate the validity and reliability of the study tools which revealed a value of 0.789 for the reliability test and a value of 0.765 for CVI then the recommended modification was done as it delineated strongly accepting the tool with omitting the items related to educational level \& occupation for the husband as it doesn't support the aims of the study and rearrange two questions to maintain sequence of questions.

Required data were recorded as well as socio-demographic data of participants (part 1), reproductive history especially warning signs/problems encountered during such periods "prelabour, intrapartum and immediately postpartum period" (part 2) as each woman and her newborn were assessed during their hospital stay and before their discharge by using the reproductive history and newborn data to detect any problems or abnormalities and if she had any problem or not (it means any problem related to health identified by the woman herself (symptoms) or signs or not either for herself or her newborn (part 2\&3). Before discharge the investigator provides the women with a follow-up card indicating the place, date of the 1st and 2nd visits, and telephone number of the investigator to call her if there had been any emergencies or problems and the investigator requested their telephone number to remind them the time of follow-up and keeping them in contact with the researcher. Then the investigator asked the woman to come immediately to the clinic according to her reported problem to be managed properly or be referred if needed.

Participants were followed up after their discharge, and asked to attend the outpatient clinic "at 7th and at 28th days postpartum". During these 2 contacts (Follow-up visits) that was carried out in the outpatient clinic, the mother was asked if she had any warning signs/problems for her newborn and asked her about the method they followed for managing danger signs and the setting for receiving management either hospital, private section or just received herbal/remedies at home. In case woman didn't attend to the clinic for follow up, the investigator called the woman asked her about the reason for not coming and if her newborn had experienced any warning signs or problems.

\subsection{Statistical analysis}

Data collected were coded, analyzed and tabulated using the Statistical Package for Social Science (SPSS version 22). The qualitative variables were presented in tables as num- bers and percentage; the figures used were portrayed in bars for qualitative variables and analyzed by Chi-square test or Fisher Exact test if $\chi^{2}$ is not valid. A $p$-value $<.05$ was considered to be statistically significant. The quantitative variables are presented as mean $\pm \mathrm{SD}$. Frequencies, correlation coefficient was applied by using r-Pearson test to identify the factors which can affect on occurrence of danger signs to detect whether there is a positive or negative correlation.

\section{RESULTS}

During the study period, a total of 150 postpartum women and their delivered newborns who were admitted to Obstetric Department at Women's Health Center, Assiut University Hospital, Egypt and accepted to participate were included and their findings were portrayed as the following: Table 1 reveals that more than two-thirds $(64 \% \& 67.3 \%)$ of the total sample aged $20-30$ years with a mean of $26.57 \pm$ 5.4 and settled in urban area respectively, and only (36\% \& 14\%) of them had secondary school \& university and above respectively with the majority of the sample (92.7) were housewives. Concerning the reproductive history of the participants, it is clear that less than one-half (41\%) of the sample were multipara with almost more than two-thirds of them $(63.3 \% \& 68.7 \%)$ had $1-3$ living children with no history of abortion respectively and the minority (12\%) among them had history of neonatal death with the most prevalent cause (38.9\%) related to hypoxia. Concerning antenatal follow-up Figure 1 portrays that the majority (94.7\%) of the mothers visited the antenatal clinic regularly during their current pregnancy and near three-quarters (71\%) of them attended mostly out-patient clinic at university hospital however the vast minority (5.3\%) of them attended private clinic as shown in Figure 2. Moreover, more than two-thirds of them visited the clinic for 3-6 times and the vast minority (7.3\%) attended the clinic for less than 3 times as in Figure 3.

Table 2 demonstrates that nearly three-quarters $(75.3 \%)$ of the total sample had antenatal danger signs, of them frequent, severe, and/or continuous headaches represents the most frequent antenatal danger signs (45.3\%), however, backache and dyspnea represent the least one $(2.7 \%)$ for each, and more than two-thirds of them (67.3\%) complains of complications arises during pregnancy, about one-fourth (24.7\%) of them developed anemia followed by (20\%) developed hypertension and convulsions. Concerning labor danger signs, the vast minority $(5.3 \%)$ of the sample had danger signs during labor as represented in prolonged labor \& dyspnea, however the labor complications represents $(22.7 \%)$ of them slightly more or less than one third $(35.3 \%, 32.4 \%$ \& 32.4\%) had vaginal bleeding, premature rupture of membrane \& 
obstructed labor respectively. Concerning postnatal danger signs, it is clear that more than two-thirds $(67.3 \%)$ of the total sample complained of postnatal danger signs and the most frequent one was dysuria and fever $>38^{\circ} \mathrm{C}(32.7 \%$ \& $28.7 \%$ respectively).

Table 1. Number and percent distribution of the studied subjects according to their socio-demographic data \& reproductive history

\begin{tabular}{|c|c|c|}
\hline Socio-demographic characteristics & $\mathbf{N}=\mathbf{1 5 0}$ & $\%$ \\
\hline \multicolumn{3}{|l|}{ Mothers' age } \\
\hline$<20$ & 24 & 16.0 \\
\hline $20<30$ & 96 & 64.0 \\
\hline $30<40$ & 26 & 17.3 \\
\hline$\geq 40$ & 4 & 2.7 \\
\hline Mean $\pm \mathrm{SD}$ (range) & \multicolumn{2}{|c|}{$26.57 \pm 5.4(18-42)$} \\
\hline \multicolumn{3}{|l|}{ Residence } \\
\hline Urban area & 101 & 67.3 \\
\hline Rural area & 49 & 32.7 \\
\hline \multicolumn{3}{|l|}{ Level of education } \\
\hline Illiterate & 37 & 24.7 \\
\hline Basic education (primary \& preparatory school) & 38 & 25.3 \\
\hline Secondary school & 54 & 36.0 \\
\hline University and above & 21 & 14.0 \\
\hline \multicolumn{3}{|l|}{ Occupation } \\
\hline Housewife & 139 & 92.7 \\
\hline Employee & 11 & 7.3 \\
\hline \multicolumn{3}{|l|}{ Size of family } \\
\hline 1-3 members & 108 & 72.0 \\
\hline 4-6 members & 34 & 22.7 \\
\hline$>6$ members & 8 & 5.3 \\
\hline \multicolumn{3}{|l|}{ Type of family } \\
\hline Nuclear & 75 & 50.0 \\
\hline Extended & 75 & 50.0 \\
\hline \multicolumn{3}{|l|}{ Reproductive history } \\
\hline \multicolumn{3}{|l|}{ Number of parity } \\
\hline Nullipara & 17 & 11.3 \\
\hline Primipara & 30 & 20.0 \\
\hline Multipara & 62 & 41.3 \\
\hline Grandmultipara & 41 & 27.3 \\
\hline Mean $\pm \mathrm{SD}$ (range) & \multicolumn{2}{|c|}{$2.36 \pm 1.57(0-7)$} \\
\hline \multicolumn{3}{|l|}{ No. of living children } \\
\hline None & 21 & 14.0 \\
\hline $1 \leq 3$ & 95 & 63.3 \\
\hline$>3$ & 34 & 22.7 \\
\hline Mean $\pm \mathrm{SD}$ (range) & \multicolumn{2}{|c|}{$2.25 \pm 1.62(0-7)$} \\
\hline \multicolumn{3}{|l|}{ No. of Abortion } \\
\hline None & 103 & 68.7 \\
\hline $1-2$ & 39 & 26 \\
\hline$\geq 3$ & 8 & 5.3 \\
\hline Mean $\pm \mathrm{SD}$ (range) & \multicolumn{2}{|c|}{$0.58 \pm 1(0-4)$} \\
\hline \multicolumn{3}{|l|}{ No. of neonatal death } \\
\hline No & 132 & 88.0 \\
\hline Yes (one child) & 18 & 12.0 \\
\hline Mean \pm SD (range) & \multicolumn{2}{|c|}{$0.1 \pm 0.3(0-1)$} \\
\hline \multicolumn{3}{|l|}{ Causes of neonatal death $(n=18)$} \\
\hline Infection & 4 & 22.2 \\
\hline Pneumonia & 4 & 22.2 \\
\hline Dyspnea & 3 & 16.7 \\
\hline Нypoxia & 7 & 38.9 \\
\hline
\end{tabular}

Published by Sciedu Press
Table 2. Number and percent distribution of the studied subjects according to their maternal danger

signs/complications during pregnancy, labor \& postpartum

\begin{tabular}{lll}
\hline Maternal danger signs/complications & No. & \% \\
\hline *Antenatal danger signs & & \\
Yes & 113 & 75.3 \\
No & 37 & 24.7 \\
Vaginal bleeding including spotting & 26 & 17.3 \\
Frequent, severe, and/or continuous headaches & 68 & 45.3 \\
Fever above 100 F (> 37.7 ${ }^{\circ}$ C) & 23 & 15.3 \\
Edema of hands, face, legs \& feet & 27 & 18.0 \\
Persistent abdominal pain & 27 & 18.0 \\
Absence or decrease fetal movement & 11 & 7.3 \\
Severe \& persistent vomiting & 15 & 10.0 \\
Painful urination & 7 & 4.7 \\
Unusual or severe abdominal pain or backaches & 22 & 14.7 \\
Backache & 4 & 2.7 \\
Vomiting & 12 & 8.0 \\
Dyspnea & 4 & 2.7 \\
Presence of complications during pregnancy & & \\
Yes & 101 & 67.3 \\
No & 49 & 32.7 \\
Hypertension and convulsions & 31 & 20.7 \\
Diabetes & 7 & 4.7 \\
Anemia & 37 & 24.7 \\
Vaginal bleeding & 25 & 16.7 \\
Bronchial asthma & 3 & 2.0 \\
Elevated Liver Enzymes & 4 & 2.7 \\
Varicose veins & 4 & 2.7 \\
Oligohydraminous & 3 & 2.0 \\
Presence of labor danger signs & &
\end{tabular}

Presence of labor danger signs

$\begin{array}{llll}\text { Yes } & 8 & 5.3\end{array}$

$\begin{array}{lll}\text { No } & 142 & 94.7\end{array}$

Prolonged labour $\quad 4 \quad 50$

$\begin{array}{lll}\text { dyspnea } & 4 & 50\end{array}$

Presence of labour complications

$\begin{array}{llll}\text { Yes } & 34 & 22.7\end{array}$

$\begin{array}{lll}\text { No } & 116 & 77.3\end{array}$

Vaginal bleeding $\quad 12 \quad 35.3$

Premature rupture of membrane $\quad 11 \quad 32.4$

$\begin{array}{lll}\text { Obstructed labour } & 11 & 32.4\end{array}$

Postnatal danger signs

$\begin{array}{lll}\text { Yes } & 101 & 67.3\end{array}$

No $\quad 49 \quad 32.7$

Fever $>38^{\circ} \mathrm{C} \quad 43 \quad 28.7$

$\begin{array}{lll}\text { Dysuria } & 49 & 32.7\end{array}$

$\begin{array}{lll}\text { Fatigue/feeling sick } & 23 & 15.3\end{array}$

$\begin{array}{lll}\text { Puerperal sepsis } & 24 & 16.0\end{array}$

$\begin{array}{lll}\text { Bleeding } & 15 & 10.0\end{array}$

$\begin{array}{lll}\text { Wound infection } & 3 & 2.0\end{array}$

$\begin{array}{lll}\text { Pelvic pain } & 22 & 14.7\end{array}$

$\begin{array}{lll}\text { Breastfeeding problems } & 18 & 12.0\end{array}$

$\begin{array}{lll}\text { Leg pain, swelling and tenderness } & 4 & 2.7\end{array}$

*The percentage exceeds $100 \%$ as more than one danger sign may be presented in each studied subjects. 


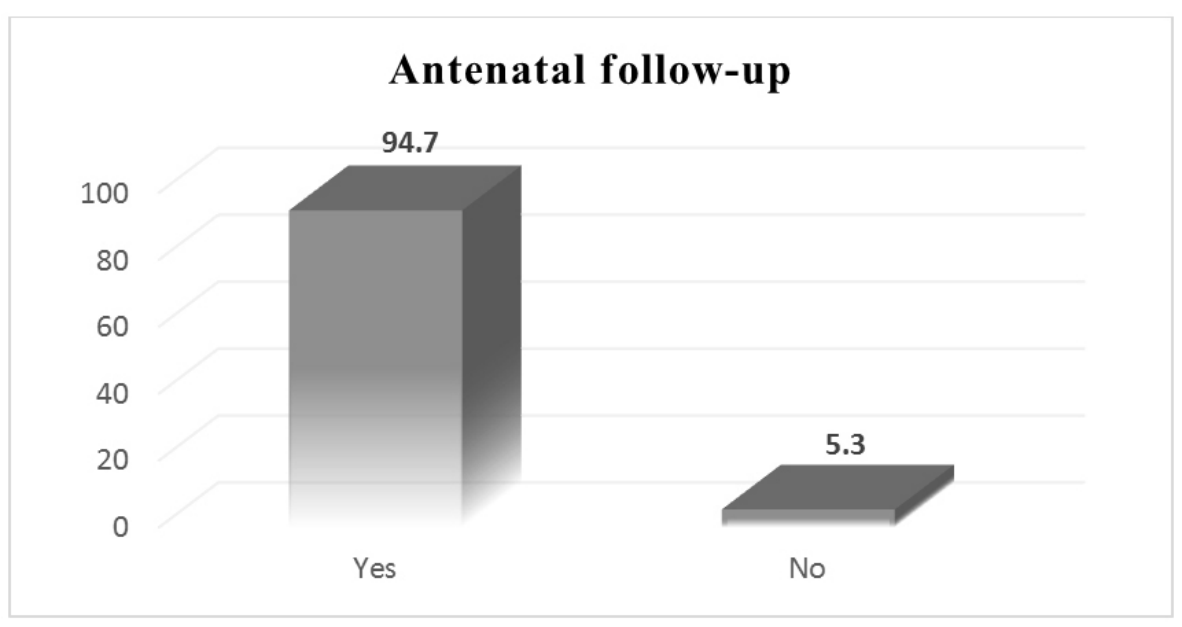

Figure 1. Distribution of the studied subjects according to their antenatal follow-up

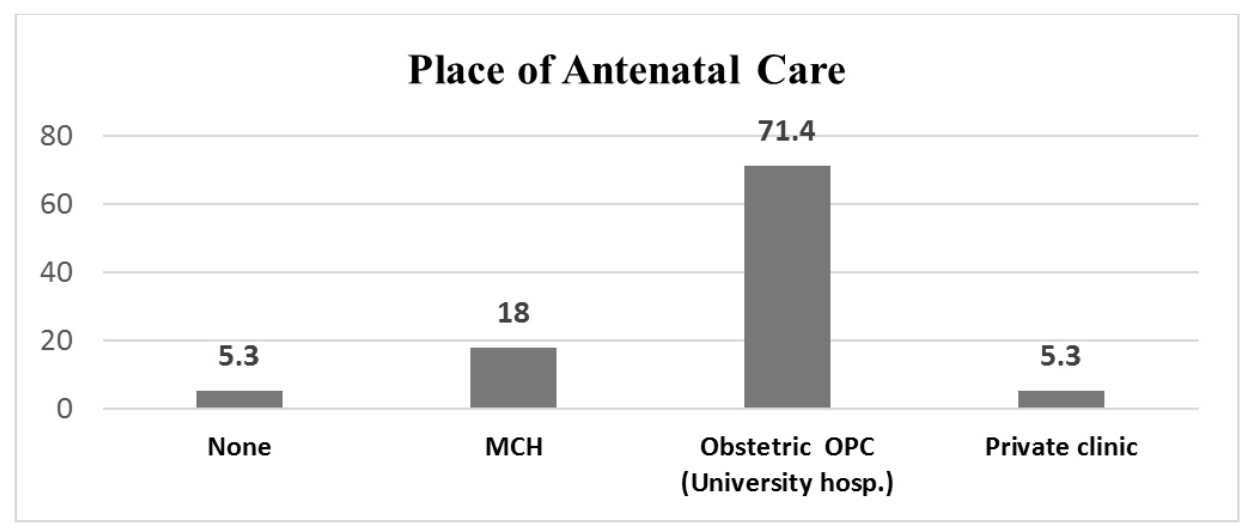

Figure 2. Distribution of the studied subjects according to their attended place of antenatal care

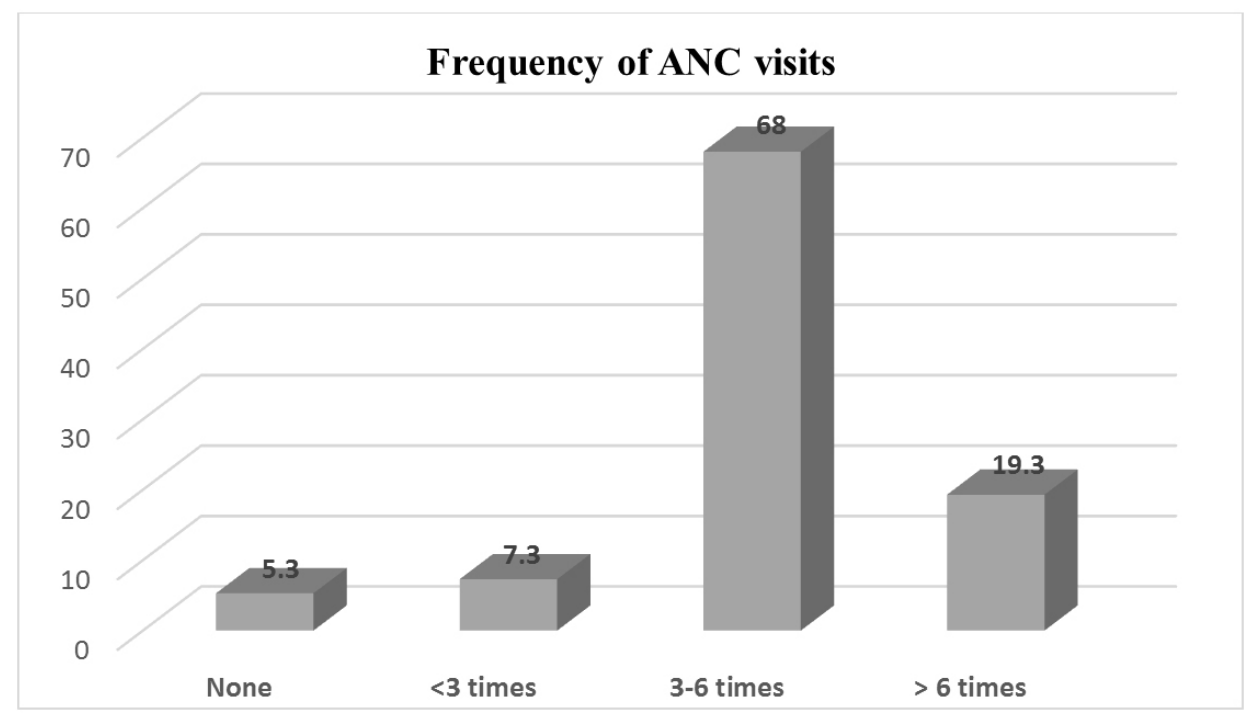

Figure 3. Distribution of the studied subjects according to their frequency of ANC visits (Mean \pm SD [range] $5.24 \pm 2.26$ $(0-12))$ 
As regards neonatal characteristics, Table 3 shows that more than half $(56.7 \%$ \& $53.3 \%)$ of the total sample their gestational age ranged between $(33-<37)$ weeks with a mean of ( $36.35 \pm 4.1$ weeks) with a neonatal weight ranged between $2,000-<3,000 \mathrm{gm}$. respectively and more than two-thirds of them had bad Apgar score (68.7\%), all of them admitted to NICU with the most frequent diagnosis for admission was respiratory distress followed by neonatal jaundice (35\% \& $24.3 \%$ respectively) and a mean stay duration of $6.21 \pm 3.6$ days mostly for a period of $3>-7$ days. It is evident that the majority (80\%) of the total sample had so early neonatal danger signs/complications with a most frequent one in the form of neonatal jaundice, followed by too weak to suck/feed, fever $>38^{\circ} \mathrm{C} \&$ difficult of breast feeding $(86.8 \%, 62 \%$, $42.1 \%$ \& $40.5 \%$ respectively) and the least one for disturbed conscious level (4.1\%).

Table 4 reveals high significant difference of neonatal danger signs apparent at 7 th day postpartum as compared to 28th day postpartum $(75.3 \% \& 12 \%$ respectively) and the most frequent danger signs was neonatal jaundice, however almost the neonatal danger signs disappear at 28th day postpartum. Regarding the places the mothers selected for managing their neonates were mostly (66.4\%) hospitals, however only less than one-third $(30.1 \%)$ of them searching for medical treatment in private clinic compared to all neonates (24 neonate) at 28 th days and the vast minority of them $(3.5 \%)$ received herbs/remedies in home.

Table 5 shows correlations between the number of neonatal danger signs at different times (at birth, early \& late) and danger signs/complications that women had from pregnancy, labor and during the postpartum period till 28th day. A positive correlation was found between number of maternal danger signs/complications during pregnancy with danger signs in their neonates at birth \& early $(r=.680, p=.001 \&$ $r=0.784, p>.001$ respectively) and a significant correlation was found regarding maternal postpartum period and neonatal danger signs at birth however, no significant difference during early neonatal period. Moreover no significat correlation was apparent between the maternal danger signs during labor and neonatal danger signs at birth, early and late.

Regarding the relationship between neonatal danger signs at different times and socio demographic data of the studied subjects, Table 6 portrays that the only significant relationship was found regarding the maternal age, education level \& maternal occupation that may affect and have a role on the neonatal danger signs. In respect to mother's age, it affects on the neonatal danger signs at early time (7th day postpartum) and for the education level it had significant effect on neonatal danger signs at birth and 7th day postpartum, however for the mother's occupation affect only early neonatal danger signs. Concerning the relationship between neonatal danger signs at different times and reproductive history of the studied subjects, it is clear that the number of parity and living children can affect significantly on neonatal danger signs at birth and early with no effect at 28th day postpartum.

Table 3. Number and percent distribution of the studied subjects by their neonatal characteristics \& danger signs

\begin{tabular}{|c|c|c|}
\hline & No. & $\%$ \\
\hline \multicolumn{3}{|l|}{ Gestational age in weeks } \\
\hline$<30$ & 4 & 2.7 \\
\hline $30<33$ & 4 & 2.7 \\
\hline $33<37$ & 85 & 56.7 \\
\hline $37<40$ & 53 & 35.3 \\
\hline$\geq 40$ & 4 & 2.7 \\
\hline Mean \pm SD (range) & \multicolumn{2}{|c|}{$36.35 \pm 4.1(13-40)$} \\
\hline \multicolumn{3}{|l|}{ Neonate weight/grams } \\
\hline$<1,000$ & 4 & 2.7 \\
\hline $1,000<2,000$ & 19 & 12.7 \\
\hline $2,000<3,000$ & 80 & 53.3 \\
\hline$\geq 3,000$ & 47 & 31.3 \\
\hline Mean $\pm \mathrm{SD}$ (range) & \multicolumn{2}{|c|}{$2,745 \pm 558.09(900-3,500)$} \\
\hline \multicolumn{3}{|l|}{ Apgar score } \\
\hline Good & 47 & 31.3 \\
\hline Bad & 103 & 68.7 \\
\hline \multicolumn{3}{|l|}{ Admission to NICU } \\
\hline Yes & 103 & 68.7 \\
\hline No & 47 & 31.3 \\
\hline \multicolumn{3}{|l|}{ Indications for admission to NICU } \\
\hline Apnea & 15 & 14.5 \\
\hline Preterm & 12 & 11.7 \\
\hline Neonatal jaundice & 25 & 24.3 \\
\hline Respiratory distress & 36 & 35 \\
\hline Respiratory distress and neonatal jaundice & 15 & 14.5 \\
\hline \multicolumn{3}{|l|}{ Duration of stay in NICU } \\
\hline $1>3$ days & 21 & 20.4 \\
\hline $3 \leq 7$ days & 48 & 46.6 \\
\hline$>7$ days & 34 & 33.0 \\
\hline $\begin{array}{ll}\text { Mean } \pm \text { SD (range) } & 6.21 \pm 3.6\end{array}$ & $0-14)$ & \\
\hline \multicolumn{3}{|c|}{ Presence of neonatal danger signs/Complications (at birth) } \\
\hline Yes & 121 & 80.7 \\
\hline No & 29 & 19.3 \\
\hline Too weak to suck /feed & 75 & 62 \\
\hline Difficult of breast feeding & 49 & 40.5 \\
\hline Jaundice & 105 & 86.8 \\
\hline Fever $>38^{\circ} \mathrm{C}$ & 51 & 42.1 \\
\hline Severe continuous vomiting & 16 & 13.2 \\
\hline Abdominal distention & 34 & 28.1 \\
\hline Diarrhea \& constipation & 30 & 24.8 \\
\hline Odor, drainage, or bleeding from the umbilical cord & 8 & 6.6 \\
\hline Excessive crying \& irritability & 12 & 9.9 \\
\hline Cyanosis & 31 & 25.6 \\
\hline Disturbed conscious level & 5 & 4.1 \\
\hline Convulsion & 34 & 28.1 \\
\hline
\end{tabular}


Table 4. Number and percent distribution of the studied subjects according to their neonate danger signs at early and late postpartum days

\begin{tabular}{|c|c|c|c|c|c|}
\hline & \multicolumn{2}{|c|}{$\begin{array}{l}\text { Early Neonatal danger signs } \\
\left(1^{\text {st }} \text { to } 7^{\text {th }} \text { days }\right)\end{array}$} & \multicolumn{2}{|c|}{$\begin{array}{l}\text { Late Neonatal danger signs } \\
\text { ( } 7^{\text {th }} \text { to } 28^{\text {th }} \text { days) }\end{array}$} & \multirow[t]{2}{*}{$p$-value } \\
\hline & No & $\%$ & No & $\%$ & \\
\hline \multicolumn{6}{|l|}{ Danger signs of neonate } \\
\hline Yes & 113 & 75.3 & 18 & 12.0 & \multirow[t]{2}{*}{$<.001^{* *}$} \\
\hline No & 37 & 24.7 & 132 & 88.0 & \\
\hline \multicolumn{6}{|l|}{ Types of danger signs } \\
\hline Dyspnea and jaundice & 11 & 7.3 & 0 & 0.0 & \multirow{9}{*}{$<.001^{* *}$} \\
\hline Vomiting and fever & 8 & 5.3 & 0 & 0.0 & \\
\hline Neonatal jaundice & 22 & 14.7 & 0 & 0.0 & \\
\hline Jaundice, inflammation of eyes & 18 & 12 & 0 & 0.0 & \\
\hline Jaundice, inflammation of eyes and continuous vomiting & 11 & 7.3 & 0 & 0.0 & \\
\hline Jaundice \& abdominal distention & 11 & 7.3 & 0 & 0.0 & \\
\hline Neonatal jaundice \&difficult breast feeding & 8 & 5.3 & 0 & 0.0 & \\
\hline Neonatal jaundice \& colicky pain & 12 & 8.0 & 12 & 8.0 & \\
\hline Neonatal chest infection & 12 & 8.0 & 12 & 8.0 & \\
\hline \multicolumn{6}{|l|}{ Methods followed for managing danger signs } \\
\hline Go to hospital for medical treatment & 75 & 66.4 & 0 & 0.0 & \multirow{3}{*}{$<.001^{* *}$} \\
\hline Go to private clinic for medical treatment & 34 & 30.1 & 24 & 100.0 & \\
\hline Used herbs/remedies in home & 4 & 3.5 & 0 & 0.0 & \\
\hline
\end{tabular}

Table 5. Distribution of the studied subjects by their neonate danger signs at different times and maternal danger signs and complications

\begin{tabular}{llll}
\hline \multirow{2}{*}{ Maternal warning signs/complications } & \multicolumn{2}{l}{ Neonatal Danger Signs } \\
\cline { 2 - 4 } & At birth & Early (at day 7th PP) & Late (at day 28th PP) \\
\hline Antenatal maternal warning signs/Complications & & 0.754 & 0.005 \\
$r$ & 0.680 & .949 \\
$p$ & $.001^{* *}$ & $<.001^{* *}$ & 0.151 \\
Maternal warning signs/Complications during Labor & & & .065 \\
$r$ & 0.017 & 0.037 & 0.136 \\
$p$ & .834 & .523 & .096 \\
PP Maternal warning signs/Complications & & & \\
$r$ & 0.887 & 0.032 & .085 \\
$p$ & $<.001^{* *}$ & &
\end{tabular}

\section{Discussion}

Several studies have examined factors contributing to neonatal mortality in settings with limited resources, however limited number of studies has focused on neonatal danger signs and complications, considering these abnormal health conditions that could eventually lead to life-threatening complications or death. ${ }^{[16]}$ Moreover, Okawa et al. ${ }^{[7]}$ emphasized that when mothers had multiple complications during pregnancy and delivery their neonates were also more likely to be born with multiple danger signs. The present study aimed to assess danger signs observed in neonates at birth, 7th and 28th days postpartum and to determine the correlation between neonatal danger signs at different times and maternal danger signs/complications during antenatal, labor and postnatal pe- riod and to identify factors associated with neonatal danger signs.

The findings of the present study revealed that the majority $(80 \%)$ of the total sample had so early neonatal danger signs/complications at birth with a most frequent finding in the form of neonatal jaundice, followed by too weak to suck /feed, fever $>38^{\circ} \mathrm{C} \&$ difficult of breast feed $(86.8 \%, 62 \%$, $42.1 \%$ \& $40.5 \%$ respectively) this finding was in the same line with Robert et al. ${ }^{[17]}$ who emphasized that poor suckling or feeding and fever were the newborn danger signs that were frequently mentioned. Apparently, these were signs that will prompt women to take their newborns to health facilities for care.

ISSN 1925-4040 E-ISSN 1925-4059 
Table 6. Relationship between neonatal danger signs at different times and socio demographic \& reproductive history of the studied subjects

\begin{tabular}{|c|c|c|c|c|c|c|c|c|c|}
\hline \multirow{3}{*}{ Demographic data } & \multicolumn{3}{|c|}{ Neonatal danger signs at birth } & \multicolumn{3}{|c|}{ Neonatal danger signs at 7th day } & \multicolumn{3}{|c|}{ Neonatal danger signs at 28th day } \\
\hline & \multirow{2}{*}{$\begin{array}{l}\text { Yes } \\
\text { No }(\%)\end{array}$} & \multirow{2}{*}{\begin{tabular}{|l|} 
No \\
No (\%)
\end{tabular}} & \multirow{2}{*}{$p$-value } & \multirow{2}{*}{$\begin{array}{l}\text { Yes } \\
\text { No }(\%)\end{array}$} & \multirow{2}{*}{$\begin{array}{l}\text { No } \\
\text { No (\%) }\end{array}$} & \multirow{2}{*}{$p$-value } & \multirow{2}{*}{$\begin{array}{l}\text { Yes } \\
\text { No (\%) }\end{array}$} & \multirow{2}{*}{\begin{tabular}{|l|} 
No \\
No (\%)
\end{tabular}} & \multirow{2}{*}{$p$-value } \\
\hline & & & & & & & & & \\
\hline \multicolumn{10}{|l|}{ Mother's age } \\
\hline$<20$ & $20(16.5)$ & $4(13.8)$ & \multirow{4}{*}{.332} & $4(10.8)$ & $20(17.7)$ & \multirow{4}{*}{$.002 * *$} & $22(16.7)$ & $2(11.1)$ & \multirow{4}{*}{.808} \\
\hline $20-30$ & $79(65.3)$ & $17(58.6)$ & & $25(67.6)$ & $71(62.8)$ & & $84(63.6)$ & $12(66.7)$ & \\
\hline $30-40$ & $18(14.9)$ & $8(27.6)$ & & $4(10.8)$ & 22 (19.5) & & $23(17.4)$ & $3(16.7)$ & \\
\hline$>40$ & $4(3.3)$ & $0(0.0)$ & & $4(10.8)$ & $0(0.0)$ & & $3(2.3)$ & $1(5.6)$ & \\
\hline \multicolumn{10}{|l|}{ Residence } \\
\hline Urban area & $79(65.3)$ & $22(75.9)$ & \multirow[t]{2}{*}{.276} & $21(56.8)$ & $80(70.8)$ & \multirow[t]{2}{*}{.114} & $92(69.7)$ & $9(50)$ & \multirow[t]{2}{*}{.095} \\
\hline Rural area & $42(34.7)$ & $7(24.1)$ & & $16(43.2)$ & $33(29.2)$ & & $40(30.3)$ & $9(50)$ & \\
\hline \multicolumn{10}{|l|}{ Mothers' education } \\
\hline Illiterate & $30(24.8)$ & $7(24.1)$ & \multirow{5}{*}{$<.001^{* *}$} & $4(10.8)$ & $33(29.2)$ & \multirow{5}{*}{$<.001^{* *}$} & $33(25)$ & $4(22.2)$ & \\
\hline Primary school & $4(3.3)$ & $10(34.5)$ & & $4(10.8)$ & $10(8.8)$ & & $12(9.1)$ & $2(11.1)$ & \\
\hline Preparatory school & $24(19.8)$ & $0(0.0)$ & & $0(0.0)$ & $24(21.2)$ & & $23(17.4)$ & $1(5.6)$ & .732 \\
\hline Secondary school & $42(34.7)$ & $12(41.4)$ & & $26(70.3)$ & $28(24.8)$ & & $46(34.8)$ & $8(44.4)$ & \\
\hline University & $21(17.4)$ & $0(0.0)$ & & $3(8.1)$ & $18(15.9)$ & & $18(13.6)$ & $3(16.7)$ & \\
\hline $\begin{array}{l}\text { Mothers' occupation } \\
\text { Housewife }\end{array}$ & $110(90.9)$ & $29(100)$ & .092 & $37(100)$ & $102(90.3)$ & $.049 *$ & $122(92.4)$ & $17(94.4)$ & .758 \\
\hline Employer & $11(9.1)$ & $0(0.0)$ & & $0(0.0)$ & $11(9.7)$ & & $10(7.6)$ & $1(5.6)$ & \\
\hline Reproductive History & & & & & & & & & \\
\hline Nullipara & $17(14)$ & $0(0.0)$ & & $0(0.0)$ & $17(15.0)$ & & $16(12.1)$ & $1(5.6)$ & \\
\hline Primipara & $16(13.2)$ & $14(48.3)$ & $<.001^{* *}$ & $8(21.6)$ & 22 (19.5) & .054 & $23(17.4)$ & 7 (38.9) & .189 \\
\hline Multipara & $55(45.5)$ & $7(24.1)$ & & $15(40.5)$ & $47(41.6)$ & & $56(42.4)$ & $6(33.3)$ & \\
\hline Grand multipara & $33(27.3)$ & $8(27.6)$ & & $14(37.8)$ & 27 (23.9) & & $37(28)$ & $4(22.2)$ & \\
\hline No. of living children & & & & & & & & & \\
\hline None & $17(14)$ & $4(13.8)$ & & $0(0.0)$ & $21(18.6)$ & & $20(15.2)$ & $1(5.6)$ & \\
\hline $1<3$ & $78(64.5)$ & $17(44.8)$ & .774 & $8(21.6)$ & $25(22.1)$ & $.015^{*}$ & $81(61.4)$ & $14(77.8)$ & .360 \\
\hline$>3$ & $26(21.5)$ & $8(27.6)$ & & $18(48.6)$ & $20(17.7)$ & & 31 (23.5) & $3(16.7)$ & \\
\hline No. of abortion & & & & & & & & & \\
\hline None & $81(66.9)$ & 22 (75.9) & & $30(81.1)$ & $73(64.6)$ & & $89(67.4)$ & $14(77.8)$ & \\
\hline $1-2$ & $32(26.4)$ & $7(24.1)$ & .326 & $7(18.9)$ & $32(28.3)$ & .096 & $35(26.5)$ & $4(22.2)$ & .484 \\
\hline$>3$ & $8(6.6)$ & $0(0.0)$ & & $0(0.0)$ & $8(7.1)$ & & $8(7.1)$ & $0(0.0)$ & \\
\hline No. of neonatal death & & & & & & & & & \\
\hline No & $106(87.6)$ & $26(89.7)$ & .76 & $37(100)$ & 95 (84.1) & $.010^{*}$ & 116 (87.9) & 16 (88.9) & .902 \\
\hline Yes (One child) & $15(12.4)$ & $3(10.3)$ & & $0(0.0)$ & 18 (15.9) & & $16(12.1)$ & $2(11.1)$ & \\
\hline Causes of neonatal de & & & & & & & & & \\
\hline Infection & $4(3.3)$ & $0(0.0)$ & & $0(0.0)$ & $4(3.5)$ & & $4(3)$ & $0(0.0)$ & \\
\hline Pneumonia & $4(3.3)$ & $0(0.0)$ & .274 & $0(0.0)$ & $4(3.5)$ & .153 & $3(2.3)$ & $1(5.6)$ & .803 \\
\hline Difficult breathing & $3(2.5)$ & $0(0.0)$ & & $0(0.0)$ & $3(2.7)$ & & $3(2.3)$ & $0(0.0)$ & \\
\hline Hypoxia & $4(3.3)$ & $3(10.3)$ & & $0(0.0)$ & $7(6.2)$ & & $6(4.5)$ & $1(5.6)$ & \\
\hline
\end{tabular}

Deaths of both mothers and infants are concentrated in the period spanning the onset of labor through the first 28 days postpartum. During those few weeks, most maternal deaths (except those due to unsafe abortion) and almost two-thirds of infant deaths occur. The intrapartum period is the most likely time for late foetuses to die. ${ }^{[18]}$ This raised issue encourage us to study in depth the neonatal danger signs and its correlation to high risk mother and identify exactly the predictors which in turn will shade the light on the most significant and critical period of neonates life. In situations like this, knowing the danger signs of neonates is one way of seeking early care. Regarding the places the mothers selected for managing their neonates were mostly $(66.4 \%)$ hospitals, however, only 34 neonates of the total numbers searching for medical treatment in private clinic during the early neonatal period compared to 24 neonates their mothers seeking help in the private clinic at 28th days postpartum and this is the only seeking help neonates during this period. These findings reflected that high risk mothers were aware and being more anxious about their neonates as the majority of them search medical treatment at hospital and private clinic and also this result may be attributed to that more than two-thirds $(67.3 \%)$ of the total sample settled in urban area and nearly half of the sample (36\% \& 14\%) had secondary school \& university. However, on the contrary, Gupta et al. ${ }^{[19]}$ mentioned that the care seeking behaviour 
among the mothers highlighted an urgent need to generate awareness among them to be able to recognize the neonatal danger signs. Concerning the educational level among the studied subjects, the finding of the present study delineates that near $75 \%$ of the study subjects were educated as only about one-fourth $(24.7 \%)$ of them were illiterate, and $25 \%$ had basic education and near half of them had secondary, university and above, this percent may justify that more than two-thirds $(66.4 \%)$ of the studied subjects had health care seeking behavior. This association is partly explained by the economic advantages and access to health care afforded by education. ${ }^{[7]}$ This is also may be explained as potential links between maternal education and reduced perinatal and neonatal mortality also include appropriate birth spacing and health-seeking behaviour, particularly for prenatal care. ${ }^{[7]}$

Similarly, a number of studies done by Worku et al. ${ }^{[20]} \& \mathrm{Ba}-$ balola et al. ${ }^{[21]}$ reported that educational status was a crucial predictor of care-seeking behaviour and maternal literacy for health related information and so maternal educational status below the secondary school level was associated with birth of neonates with danger signs. On the contrary, Kayode et al. ${ }^{[22]}$ in a previous Ghanaian study, found that maternal educational status was not associated with neonatal death.

Concerning the reproductive history of the mothers, more than two-thirds of them visited the clinic for 3-6 times, this finding may reflect good awareness of mothers with the neonatal danger signs and rationalize that more than two thirds of the studied subjects seeking medical care at hospitals in the 7th day postpartum. In this respect, Okawa et al. ${ }^{[6]}$ reported that fewer than four ANC visits resulted in a higher likelihood of neonates being born with danger signs. More than $40 \%$ of women had experienced complications during pregnancy, while only $55 \%$ of the women had received the six identified components of essential antenatal services. This finding indicates that fewer ANC visits result in delayed diagnosis and management of potential complications. This result was in contrary to our findings as more than two-thirds of them visited the clinic for 3-6 times and the vast minority of the sample $(7.3 \%)$ attended the clinic for less than 3 times as in Figure 3 and despite of being attended the antenatal clinic frequently the percentage of neonatal danger signs was high, this may be attributed to the low quality of the received antenatal care. On the other hand, one may wonder whether the obstetric care system in the Women health Center, Assiut need to be critically revised. As more than two-thirds of women had complications during pregnancy and complained of danger signs during the pospartum period. However, no significant correlation was reported for those who had complications during labor and occurrence of neonatal danger signs, this may be emphasized as the skilled care at delivery has been associated historically with lower neonatal mortality rates. ${ }^{[23]}$ However this finding was disagreed by Okawa et al. ${ }^{[7]}$ who reported that a significant number of maternal complications was positively correlated with number of danger signs in their neonates $(r=0.20 ; p$ $<.001)$ during the birth period and complications observed within the first six weeks $(r=0.19 ; p<.001)$. Moreover, As regards the associated maternal risk factors Manisha \& Rajeev ${ }^{[24]}$ reported in their study that high risk pregnancies represent the main causes of perinatal mortality which affect negatively on neonatal mortality and they added that most of the perinatal deaths were associated with lack of education (45\%). Moreover, a number of antenatal and intrapartum factors have been reported in the literature to be significantly associated with perinatal and neonatal deaths. ${ }^{[25]}$

In this respect, the present findings highlighted that the level of education and occupation of the mother affect significantly on neonatal danger signs during both periods (at birth $\&$ the first 7 th days postpartum) and the maternal age affect only on early neonatal danger signs. These findings may add more concern on other confounding socio-demographic and obstetrical factors that may have an impact on the occurrence of neonatal danger signs especially at birth \& within the 7 th days postpartum.

\section{Conclusion}

It can be concluded that a highly percentage of neonates were born with danger signs and neonatal jaundice represented the most frequent one. Maternal factors (antenatal and postpartum danger signs) can be used to predict neonatal danger signs at birth and 7 th days postpartum with marked decline at 28th day postpartum and educational level, maternal age, mothers' occupation, number of parity, living children and abortion were considered associated factors affect significantly on neonatal danger signs at birth and early neonatal period.

\subsection{Recommendations}

Based on the findings of the present study, it is proposed to recommend the following:

- Conducting in-service training program for midwives who are giving care to high risk women during (pregnancy, labor and postpartum period) to limit the number of adversely affected neonates this enables midwives to be skilled with access to the appropriate level of neonatal care when needed.

- Preconception and antenatal care provide an opportunity to reduce risk factors for neonatal mortality and morbidity. Counseling on risks to a healthy pregnancy and birth preparedness, emphasizing the importance 
of a safe delivery and highly aware mothers who will be able to recognize signs of illness, and when they appear, promptly seek appropriate medical assistance that will in turn improve neonate's quality of health.

- Eeffective and timed intervention among high risk cases with appropriate intrauterine monitoring through implementation of simple, proven interventions during the antenatal, intrapartum and postpartum periods on a broader scale as timely delivery of the babies are important to reduce neonatal danger signs at birth, early and late.

\subsection{Recommendations related further studies}

- Further studies should be conducted to explore the factors contributing to poor uptake of PNC during the neonatal period.

- Further studies should be implemented to audit health care workers (midwives) providing comprehensive mother friendly education and care to all women, especially expectant mothers.

\section{ACKNOWLEDGEMENTS}

We would like to acknowledge the study participants for their participation and without them, the research would not be accomplished and our sincere gratitude goes to our graduates at Women Health centre who devoted their precious time to help us in data collection.

\section{CONFLICTS OF INTEREST Disclosure}

The authors declare that they have no competing interests.

\section{REFERENCES}

[1] Ezeh OK, Agho KE, Dibley MJ, et al. Determinants of neonatal mortality in Nigeria: evidence from the 2008 demographic and health survey. BMC Public Health. 2014; 14: 521. PMid:24886517 https://doi.org/10.1186/1471-2458-14-521

[2] UNICEF. Committing to child survival: a promise renewed. New York: UNICEF; 2014

[3] Mohamed E, Soliman A, El-Asheer O. Predictors of mortality among neonates admitted to neonatal intensive care unit in pediatric Assiut University Hospital. Egypt Journal of American Science. 2011; 7(6).

[4] WHO. EMRO. Country profiles. Health status Indicators; 2010.

[5] Hafez S, Dorgham L, Sayed S. Profile of High Risk Pregnancy among Saudi Women in Taif-KSA. World Journal of Medical Sciences. 2014; 11(1): 90-97.

[6] Moss W, Darmstadt GL, Marsh DR, et al. State of the Art: Research Priorities for the Reduction of Perinatal and Neonatal Morbidity and Mortality in Developing Country Communities. Journal of Perinatology. 2002; 22: 484-495. PMid:12168128 https: //doi.org/10.1038/sj.jp.7210743

[7] Okawa S, Ansah EK, Nanishi K, et al. High incidence of neonatal danger signs and its implications for postnatal Care in Ghana: A cross-sectional study. PLos One. 2015; 10(6): e 0130712.

[8] Hibstu DT, Siyoum YD. Knowledge of obstetric danger signs and associated factors among pregnant women attending antenatal care at health facilities of Yirgacheffe town, Gedeo zone, Southern Ethiopia. Arch Public Health. 2017 Aug 14; 75: 35. PMid:28811893

[9] Adem N, Berhe KK, Tesfay Y. Awareness and Associated Factors towards Neonatal Danger Signs among Mothers Attending, Public Health Institutions of Mekelle City, Tigray, Ethiopia. J Child Adolesc Behav. 2017; 5: 365.

[10] Behal M, Vinayak R. Maternal risk factors for perinatal mortality. Indian Journal of Obstetrics and Gynecology Research. April-June 2015; 2(2): 92-96.

[11] Bhutta ZA, Darmstadt GL, Hasan BS, et al. Community-based interventions for improving perinatal and neonatal health outcomes in developing countries: a review of the evidence. Pediatrics. 2005; 115 (2 Suppl): 519-617.
[12] World Bank. Mortality rate, neonatal (per 1,000 live births). World Bank Data. Available from: http://data.worldbank.org/ind icator/SH.DYN. NMRT [cited 7 May 2014]

[13] Bansal P, Verma D, Bansal A. Prenatal risk score in high risk pregnancy cases and perinatal outcome: a study from South India. International Journal of Reproduction, Contraception, Obstetrics and Gynecology, Bansal P et al. Int J Reprod Contracept Obstet Gynecol. 2016 Nov; 5(11): 3889-3992.

[14] Jemberia1 MM, Berhe ET, Mirkena HB, et al. Low level of knowledge about neonatal danger signs and its associated factors among postnatal mothers attending at Woldia general hospital, Ethiopia Journal of Maternal Health, Neonatology, and Perinatology. 2018.

[15] Obstetrics \& Gynecology Department, Assiut University Data Base 2017.

[16] Tuncalp O, Hindin MJ, Adu-Bonsaffoh K, et al. Understanding the Continuum of Maternal Morbidity in Accra, Ghana. Matern Child Health J. 2014; 18: 1648-57. PMid:24347090 https://doi .org/ $10.1007 / \mathrm{s} 10995-013-1405-8$

[17] Robert KL, Yidana A. Exploring Women Knowledge of Newborn Danger Signs: A Case of Mothers with under Five Children. Public Health Research. 2014; 4(5): 195-202.

[18] Barbara J, Adetokunbo O. Improving Birth Outcomes: Meeting the Challenge in the Developing World: Judith R. Bale, Committee on Improving Birth Outcomes; Board on Global Health; Institute of Medicine; THE NATIONAL ACADEMIES PRESS Washington, 2003.

[19] Gupta P, Srivastava VK, Kumar V, et al. Care seeking behaviour of mothers during the illness of newborn in urban slums of Lucknow city. Indian Journal of Community Health. 2012.

[20] Worku AG, Yalew AW, Afework MF. Factors affecting utilization of skilled maternal care in Northwest Ethiopia: a multilevel analysis. BMC Int Health Hum Rights. 2013; 13: 20. PMid:23587369 https://doi.org/10.1186/1472-698X-13-20

[21] Babalola S, Fatusi A. Determinants of use of maternal health services in Nigeria, looking beyond individual and household factors. BMC Pregnancy Childbirth. 2009; 9: 43. PMid:19754941 https://doi.org/10.1186/1471-2393-9-43

[22] Kayode GA, Ansah E, Agyepong IA, et al. Individual and community determinants of neonatal mortality in Ghana: a multilevel 
analysis. BMC Pregnancy Childbirth. 2014; 14: 165. PMid:24884759 https://doi.org/10.1186/1471-2393-14-165

[23] World Health Organization. Making Pregnancy Safer. Geneva: WHO; 2000 .

[24] Behal M, Vinayak R. Maternal risk factors for perinatal mortality.
Indian Journal of Obstetrics and Gynecology Research. 2015 AprilJune; 2(2): 92-96.

[25] Mohamed EM, Asmaa MA, Soliman OM. Predictors of mortality among neonates admitted to neonatal intensive care unit in pediatric Assiut University Hospital, Egypt. Journal of American Science. 2011; 7(6). 